\title{
Food-grade controlled lysis of Lactococcus lactis for accelerated cheese ripening
}

\author{
Pascalle G.G.A. de Ruyter, Oscar P. Kuipers*, Wilco C. Meijer, and Willem M. de Vos \\ 'Department of Biophysical Chemistry, Genetics Group, and 'Department of Microbiology, NIZO, P.O. Box 20, 6710 BA Ede, The Netherlands. \\ ${ }^{*}$ Corresponding author (e-mail: kuipers@nizo.nl).
}

Received 24 January 1997; accepted 7 July 1997

\begin{abstract}
An attractive approach to accelerate cheese ripening is to induce lysis of Lactococcus lactis starter strains for facilitated release of intracellular enzymes involved in flavor formation. Controlled expression of the lytic genes lyt $A$ and $l y t h$, which encode the lysin and the holin proteins of the lactococcal bacteriophage $\Phi U S 3$, respectively, was accomplished by application of a food-grade nisin-inducible expression system. Simultaneous production of lysin and holin is essential to obtain efficient lysis and concomitant release of intracellular enzymes as exemplified by complete release of the debittering intracellular aminopeptidase N. Production of holin alone leads to partial lysis of the host cells, whereas production of lysin alone does not cause significant lysis. Model cheese experiments in which the inducible holinlysin overproducing strain was used showed a fourfold increase in release of L-Lactate dehydrogenase activity into the curd relative to the control strain and the holin-overproducing strain, demonstrating the suitability of the system for cheese applications.
\end{abstract}

Keywords: cheese ripening, lysin, holin, Lactococcus lactis

Lactic acid bacteria are gram-positive bacteria that are widely used in a variety of dairy fermentation processes. They contribute to flavor formation and texture development while protecting the product from spoilage organisms. Notably, strains of the lactic acid starter bacterium Lactococcus lactis are of great economic importance because of their world-wide use in cheese making. It is assumed that the lysis of lactococci during cheese ripening results in the release of intracellular proteolytic and esterolytic enzymes, which contribute to flavor development. This process is relatively slow and enhancement of the rate of lysis could result in accelerated cheese ripening. In addition, lysis of starter bacteria is an attractive possibility for secretion of overproduced intracellular enzymes from lactococci in a food-grade manner ${ }^{1,2}$. Lysis can be achieved by host-encoded autolysis or through the action of lytic bacteriophages ${ }^{3}$. Both processes require hydrolytic enzymes, e.g., amidases or muramidases, that gain access to the cell wall either via direct secretion ${ }^{4}$ or via cell-membrane disruption by a holin ${ }^{5}$. Holin genes are generally found immediately adjacent to lysin genes and code for small peptides with high structural similarity ${ }^{6.8}$. Lysis induced by bacteriophage infection has been combined with enhanced gene expression in $L$. lactis, yielding a system that can be exploited for accelerated cheese ripening. However, controlled production of only the lytic proteins offers a noninfective approach for developing lactococcal strains that lyse upon demand. Initial attempts to exploit the lysin of $\Phi M L 3$ in $L$. lactis were unsuccessful because a tightly controlled gene expression system was not available ${ }^{20,11}$.

Recently, an inducible expression system has been developed for $L$. lactis that is based on the food-grade antimicrobial peptide nisin $^{2,12,13}$. Subinhibitory amounts of nisin can induce transcription of genes cloned under control of the nis $A$ promoter, in a linear dose-response. This is accomplished via signal transduction mediated by a two-component regulatory system comprising the histidine kinase NisK and the response regulator Nis $\mathrm{R}^{2,12,13}$. This tightly controlled system allows for the construction of improved and specialized cheese starter cultures that will release their intracellu- lar enzymes efficiently at an early stage in the cheese curd. We report the construction of lactococcal strains that express the holin (lytH) and the lysin (lytA) genes of bacteriophage QUS3 (ref. 14) in a controlled manner, permitting induced lysis. Furthermore, we show that the lytH gene encodes a protein that itself is capable of disrupting the cellular membrane, thereby facilitating release of intracellular enzymes without disturbing other starter strains.

\section{Results}

Nisin induced lysis: Effect of holin and lysin production on growth and viability of $L$. lactis. The adjacent genes lytA, encoding a lysin, and $l y t H$ (previously designated orf2) encoding a putative holin, from the $L$. lactis bacteriophage $\Phi U S 3$, have the gene order lytHA, which are separated by $150 \mathrm{bp} \mathrm{p}^{14}$. Both genes were cloned either individually or as the lytic cassette $l y t H-l y t A$ into the expression vector pNZ8010 (ref. 2) under control of the nisin-inducible nis $A$ promoter, resulting in plasmids pNZ8011 (lytHA), pNZ8012 (lytA), and pNZ8013 (lytH), respectively. These plasmids were introduced in strain $L$, lactis NZ3900, an MG1363 derivative containing the nisRK signal transduction genes, integrated in the pepN locus on the chromosome $e^{13,13}$. The addition of the inducer peptide nisin $(0.01 \mu \mathrm{g} / \mathrm{ml})$ to growing cells of strain NZ3900 harboring the expression plasmid without the lytic genes did not cause any effect on growth (data not shown). In contrast, the addition of the same amount of nisin to strain NZ3900 harboring pNZ8011 containing the lytic cassette lytH-lytA resulted in a decrease in optical density (Fig. 1A). The number of colony forming units dropped more than 10,000-fold, indicative of cell lysis (data not shown). The extent of lysis was dependent on the amount of nisin added (Fig. 1A), and lysis could be induced throughout the exponential growth phase although the extent of lysis varied (Fig. 1B).

As expected, induction of only lytA expression using $0.01 \mu \mathrm{g}$ nisin/ml did not cause any significant lysis of $L$. lactis NZ3900 cells harboring pNZ8012 (Fig. 2A). However, the induction of lytH expression using $0.01 \mu \mathrm{g}$ nisin $/ \mathrm{ml}$ almost immediately halted the growth of cells harboring pNZ8013 (Fig. 2A). Because the ribosome binding site of 
the $l y t H$ gene does not conform to the consensus for $L$. Lactis, plasmids were constructed that contained the nisA promoter translationally fused to the lytH gene (pNZ8036) or the lytH-lytA cassette (pNZ8038). This approach has been shown to improve translation during expression of the Escherichia coli gusA gene in $L$. lactis'. Following induction of strain NZ3900 harboring pNZ8036 with nisin $(0.01 \mu \mathrm{g} / \mathrm{ml})$, the cells stopped growing and the slight decrease in optical density (similar to pNZ8013, Fig. 2A) was associated with a tenfold decrease in cfu (data not shown). To obtain food-grade constructs, the cat184 marker that is used in the constructs pNZ8036 and pNZ8038 was replaced by the lacF marker gene ${ }^{15}$. A process in which only DNA of the same species as the host organism is used, thereby reducing the risk of introducing possible toxic or otherwise undesirable features in the foodgrade host strain is called self-cloning. The resulting plasmids were stably maintained in the lacF-deficient strain L. lactis NZ3900 and showed the expected lysis of cells upon induction (data not shown).

Lysis and release of intracellular proteins. To analyze whether nisin-induced lysis resulted in the release of intracellular enzymes, the activity of overproduced aminopeptidase $\mathrm{N}$ (PepN) was determined in the medium and compared with that present inside the cells. PepN is an intracellular enzyme that has debittering activity ${ }^{16,17}$. For this pur- pose we used the L. lactis strain NZ3900 harboring plasmids pN78038 or $\mathrm{pNZ} 8036$, containing the $l y t H-l y t A$ cassette or only lytH, respectively, together with the compatible plasmid pNZ1120 that overexpresses the pepN gene under control of its own constitutive promoter ${ }^{16}$. Cells harboring only the pepN-plasmid $\mathrm{pNZ1120}$ and uninduced cells were used as controls and showed only a slightly increased $(<10 \%)$ PepN activity in the medium, probably due to spontaneous lysis of the cells (Fig. 2B). Cells coexpressing lytH and lytA lysed after induction with $0.01 \mu \mathrm{g}$ nisin $/ \mathrm{ml}$ showed an increasing concentration of PepN in the medium. Five hours after induction more than $90 \%$ of total PepN produced was released into the medium (Fig. 2B). When the holin gene was expressed, only a portion of the PepN (up to $30 \%$ ) was released in the medium (Fig. 2B).

Extracellular LytA causes lysis of L. lactis. Addition of the muramidase LytA to $L$. lactis cells results in lysis ${ }^{14}$. To exploit this trans-acting lytic mechanism, we grew equal amounts of cultures of $L$. lactis NZ3900 carrying pNZ8038 (lytHA) or pNZ8040 (ref. 2), which contains the pep $N$ gene cloned under control of the nis $A$ promoter. Following induction with nisin $(0.01 \mu \mathrm{g} / \mathrm{ml})$ and without addition of nisin, the specific PepN activity was determined in the medium (Fig. $3 A$ ). The induced culture showed a dramatic increase of PepN in the medium and apparent linear growth, probably due to lysis of the cells carrying the lytic cassette and partial lysis or growth arrest of the PepN-overproducing cells. A similar experimental setup was used with a strain carrying the $l y t H$ expressing plasmid (pNZ8036) together with NZ3900 carrying the pepN overexpression plasmid pNZ8040 (Fig. 3B). Only a slight increase in PepN activity was observed after induction, probably caused by spontaneous lysis. In the control strain NZ3900 carrying pNZ8020, containing only the nis $A$ promoter, a similar degree of spontaneous lysis of the PepN-overproducing cells was observed (Fig, 3C). Because the pepN gene was controlled by the nis $A$ promoter in these experiments, strain NZ3900 carrying pNZ8038 (lytHA) was also grown together with strain MG1363 carrying pNZ1120, which constitutively produces PepN. Nisin addition resulted in an increasing extracellular PepN activity (Fig. 3D), the level of which was lower than that observed in the previous experiment (Fig. 3A) because of the relatively low level of constitutive PepN production by cells harboring pNZ1120. Generally, induction of lysis can also be achieved by adding small amounts of culture broth of a nisin-producing $L$. lactis strain or even by adding a small aliquot of a nisin-producing strain to the described cultures (data not shown).

To investigate the significance of the developed system in a real product environment, a cheese model system was used, in which three types of model cheeses were produced, each with a different $L$. lactis adjunct starter culture containing either a negative control plasmid, a holin-overexpression plasimid, or a lysin-holin-overexpression plasmid. As a reporter molecule the large enzyme $\mathrm{L}$-Lactate dehydrogenase $(\mathrm{LDH})$ was used, because release of this enzyme would also indicate facilitated release of smaller enzymes. The total release of LDH activity in all cases increased significantly in the model cheese during four days of ripening (Fig. 4). The release obtained in the model cheese that was manufactured with the holin-lysin overproducing strain was approximately fourfold higher than the released fraction observed in model cheese manufactured with the control and with the holin-overproducing strain (Fig. 4). This same trend was observed in the released $L D H$ fraction in the additional whey formed after packaging, indicating that the extraction procedure itself did not affect the release of $\mathrm{LDH}$ (data not shown). These results show that the release of an intracellular large enzyme like $\mathrm{LDH}$ is caused by lysis
Figure 2. (A) Growth curve of strain L lactis NZ3900 carrying pNZ8011 (yth-lytA,A), pNZ8012 (yt4, 1 ), or pNZ8013 (yth, $)$ ), after induction with $0.01 \mu \mathrm{g} / \mathrm{ml}$ nisin (induction after 4 hours [arrow]), or without nisin (+). (B) Intracellular enzyme release. The percentage of total aminopeptidase $\mathrm{N}$ activity (specific activity in units/OD $/ \mathrm{D}_{\text {ero }}$ ) present in the culture supernatant of strain NZ3900 carrying pNZ1120 (pepN,A), pNZ1120 (pepM) together with pNZ8038 (lyth-lytA, ), or pNZ1120 (pepM) together with pNZ8038 (ytH, $\square$ ), after induction (arrow) with $0.01 \mu \mathrm{g} / \mathrm{ml}$ nisin. 

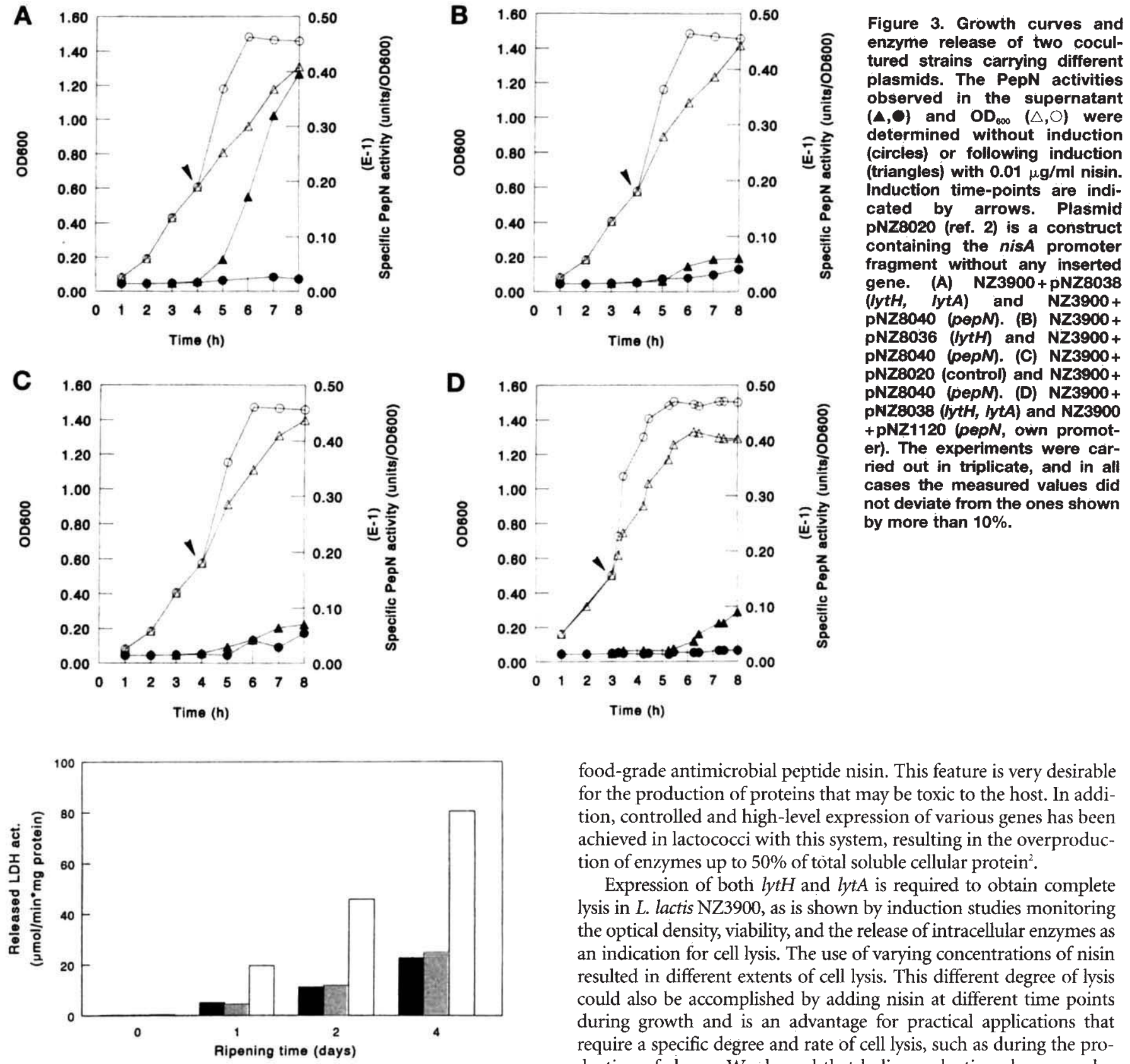

Figure 4. Total released L-Lactate dehydrogenase (LDH) activity ( $\mu \mathrm{mol} / \mathrm{ml} \times \mathrm{min}$ ) in model cheese after pressing (time 0 ) and after 1, 2, and 4 days ripening at $13^{\circ} \mathrm{C}$. Model cheeses were manufactured with $2 \%$ L. lactis ssp. cremoris SK110 as starter culture complemented with either $0.4 \%$ NZ3900 + pNZ8020 (black bar), $0.4 \%$ NZ3900 + pNZ8036 (grey bar), or $0.4 \%$ NZ3900 +pNZ8038 (white bar). Nisin A (1 $\mu \mathrm{g} / \mathrm{L}$ ) was added $75 \mathrm{~min}$ after inoculation of the cheese milk. LDH measurements were performed in triplicate, and standard errors in no case exceeded $10 \%$ of the indicated values.

of the adjunct starter strain itself, containing the lytic cassette (lytHL), and probably by partial lysis of the SK1 10 starter culture.

\section{Discussion}

We used the lytic genes of the lactococcal bacteriophage TUS3 in combination with a nisin-inducible expression system, to accomplish controlled lysis of lactococcal cells. This expression system has the advantage that it allows the gene of interest to be present and silent in the host until the system is triggered by subinhibitory amounts of the

food-grade antimicrobial peptide nisin. This feature is very desirable for the production of proteins that may be toxic to the host. In addition, controlled and high-level expression of various genes has been achieved in lactococci with this system, resulting in the overproduction of enzymes up to $50 \%$ of total soluble cellular protein ${ }^{2}$.

Expression of both $l y t H$ and $l y t A$ is required to obtain complete lysis in L. lactis NZ3900, as is shown by induction studies monitoring the optical density, viability, and the release of intracellular enzymes as an indication for cell lysis. The use of varying concentrations of nisin resulted in different extents of cell lysis. This different degree of lysis could also be accomplished by adding nisin at different time points during growth and is an advantage for practical applications that require a specific degree and rate of cell lysis, such as during the production of cheese. We showed that holin production alone can also lead to partial lysis of the cells, probably by disrupting the membrane, thereby releasing part of the intracellular content into the medium (Fig. 1B). LytH is likely to have a holin function similar to the $\mathrm{S}$ protein of the $E$. coli phage lambda ${ }^{5,6}$ (i.e., rendering the murein substrate in the lactococcal cell wall accessible to the lysin). This can be an advantage for practical applications because the holin-producing cells do not lyse immediately and therefore are metabolically active for a longer period as compared with cells carrying the lytic cassette.

The amidase LytA of $\Phi U S 3$ causes lysis of lactococci when present in the medium but does not cause significant lysis when produced within the lactococcal cells, because it is not secreted due to lack of a signal sequence and the absence of a holin. This property, known as lysis from without, has been used to achieve controlled release into the external growth medium of intracellularly (over)expressed proteins, such as PepN present in other lactococci. By use of an adjunct starter culture that contains the holin and lysin genes under control of the nisin inducible promoter, other industrial strains of L. lactis present in a fermented product will also lyse after induction with nisin and 
release their intracellular contents. The latter will not happen if partial lysis by the holin-producing adjunct culture is permitted to occur, because these cells will not damage the surrounding bacteria. This can be advantageous when only release of enzymes of the adjunct starter culture is desired. Model cheeses were made that exhibited a fourfold faster release of $\mathrm{LDH}$ into the curd when the holin-lysin-producing strain was used relative to the other two strains, which is indicative of facilitated release of relevant flavor-forming enzymes in the curd. Instead of adding purified nisin, it is also possible to add small amounts of a fermentation broth from a nisin-producing $L$. lactis strain or even more simply to include a small amount of nisin-producing bacteria in the starter culture, which enables in situ inducer production. It might also be worthwhile to implement nisin-inducible holin-lysin systems in other adjunct starter cultures such as lactobacilli, streptococci, enterococci, and leuconostocs.

Cheese ripening costs, which amount to $\$ 13,000,000$ per week for the annual production of Gouda cheese in the Netherlands, may be reduced significantly by application of the adjunct starter cultures described here.

\section{Experimental protocol}

Bacterial strains and culture conditions. E. coli $\mathrm{MC} 1061$ was grown in Lbroth based medium with aeration at $37^{\circ} \mathrm{C}^{1,2,9}$. L. lactis strains were routinely grown at $30^{\circ} \mathrm{C}$ in media based on M17 (Merck, Darmstadt, Germany) supplemented with $0.5 \%$ (wt/vol) glucose (GM17). Chloramphenicol and erythromycin were used if appropriate at a concentration of $10 \mu \mathrm{g} / \mathrm{ml}$ ). For model cheese making, cells of strain $L$. lactis ssp. cremoris SK110 were used, which were precultivated for $20 \mathrm{~h}$ at $20^{\circ} \mathrm{C}$ in milk.

Molecular cloning procedures. E. coli MC1061 was used as an intermediate host for cloning and was handled using standard techniques ${ }^{19}$. Plasmid DNA was introduced into L. lactis by electroporation ${ }^{20}$. Plasmid DNA was isolated from protoplasts of $L$. lactis ${ }^{21}$. Restriction fragments and plasmids were analyzed by agarose gel electrophoresis and purified by use of the USBioclean kit (U.S. Biochemical Corp., Cleveland, $\mathrm{OH}$ ).

Construction of plasmids. A $1300-b p$ SspI-EcoRI fragment containing the lyt $H$ and $l y t A$ genes was isolated from pNZ1308 (ref. 14), treated with Klenow polymerase and cloned in pUC19, which was digested with HincII, to construct pUC19I. A 990-bp EcoRV fragment containing the lytA gene from pNZ1308 was also cloned in pUC19 digested with HincII, generating pUC19II. A 500-bp Sau3AI-Sspl fragment containing the lytH gene was isolated from pNZ1308 and cloned in pUC19, digested with Hincil, generating pUC19III. Subsequently, the lytH-lytA cassette and the lytH gene were isolated respectively as 1300 - and 500 -bp BamHI-EcoRI fragments from pUC19I and pUC19II and cloned under control of the nisA promoter in the expression vector pNZ8010 (ref. 2), which had been digested with BamHI and EcoRI, to construct plasmid pNZ8011 (lytH-lytA) and pNZ80I3 (lytH). Plasmid pNZ8012 was constructed by cloning a 990-bp XbaIPstI fragment from pUC19II in pNZ8010 which had been digested with XbaI and PstI. For construction of the translational fusion vectors, an $\mathrm{NcoI}$ site was introduced at the ATG start codon of the lytH gene by use of PCR mutagenesis. The gene was amplified by using approximately $100 \mathrm{ng}$ pNZ8011 as a template and two primers: 5'-GCAAACAACCATGGTAACTAGAATG (containing two substitutions [boldface] generating the new Ncol site [underlined]) and 5'-CGAAGTACAACAAGCTTACGTCAATC (containing a HindIII site [underlined]). The primers are complementary to positions 353 to 378 and position 588 to 562 (according to the numbering of ref. 14). The amplified lytH gene was cloned as an NcoI-HindIII fragment into pNZ8032 (ref. 2), which was digested with NcoI and HindIII generating pNZ8036. For the construction of pNZ8038, the 1.2-kb $B$ bsI-Xhol fragment of pNZ8011 containing part of lytH and complete lytA was cloned into the $3.1-\mathrm{kb}$ vector fragment of pNZ8036, digested with BbsI and XhoI.

Nisin induction and monitoring of lysis. An overnight culture of $L$. lactis containing an expression plasmid was inoculated into fresh medium (GM17 with chloramphenicol $10 \mu \mathrm{g} / \mathrm{ml}$ ) and grown until an $A_{6000 m}$ of 0.5 was reached. The cells were induced with different concentrations $(0.02,0.01$, 0.005 , or $0.001 \mu \mathrm{g} / \mathrm{ml}$ ) of nisin A (referred to as nisin) or not treated. At several time intervals, cells were harvested and cell extracts were prepared? These extracts or the culture supernatants were used for quantitative determination of aminopeptidase $\mathrm{N}$ activity using lysyl-p-nitroanilide (Fa. Bachem, Bubendorf, Switzerland) as a chromogenic substrate for PepN ${ }^{16}$. To exclude possible strain dominance in coculture experiments, strains were grown separately and mixed when an $A_{6 \infty 0}$ of 0.5 was reached. In the mixed culture experiments with strains NZ3900 carrying pNZ8038 and MG1363 carrying pNZ1120, the individual strains were grown until an $A_{600}$ of 0.5 was reached, cells were spun down and suspended together in fresh GM17 prewarmed at $30^{\circ} \mathrm{C}$ without antibiotics in the absence or presence of nisin.

Model cheese manufacturing. Model cheese was manufactured from pasteurized $\left(30 \mathrm{~min}, 63^{\circ} \mathrm{C}\right.$ ) Nilac (a highly standardized low heat spray powder; Netherlands Institute for Dairy Research [NIZO], Ede, The Netherlands) skim milk supplemented with $0.1 \%$ yeast-extract. Cheese milk was inoculated with $2 \%$ of a full-grown culture of $L$. lactis ssp. cremoris SK110 complemented with either $\quad 0.4 \% \quad \mathrm{NZ3} 300(\mathrm{pNZ8020}), \quad 0.4 \% \quad \mathrm{NZ3900}(\mathrm{pNZ8036})$, or $0.4 \%$ NZ3900(pNZ8038) of full grown cultures and incubated at $30^{\circ} \mathrm{C}$. Sixty minutes after inoculation $0.023 \%$ rennet was added, and $75 \mathrm{~min}$ after incubation $1 \mu \mathrm{g} / \mathrm{L}$ nisin A was added for induction of the lytic genes. After 25-min setting of the milk, the curd was subsequently cut, drained, pressed, vacuumized, and stored at $13^{\circ} \mathrm{C}$. LDH activity was assayed ${ }^{22}$. Released enzyme activity was determined in the whey, which was separated during ripening, and in the curd. The curd sample was diluted fivefold in $2 \%$ sodium citrate buffer (wt/vol) and subsequently homogenized for $5 \mathrm{~min}$ in a stomacher (Lab-Blender 400, Seward London). The sample was centrifuged for $10 \mathrm{~min}$ at $10,000 \mathrm{G}$ to remove whole cells.

\section{Acknowledgments}

We are grateful to Roland Siezen and Michiel Kleerebezem for critically reading the manuscript and to Liesbeth Bijl and Bert van de Bunt for expert technical assistance. This work was partly supported by the Mesdag Foundation (Leeuwarden, The Netherlands).

1. de Vos, W.M. and Simons, G. 1994. Gene cloning and expression systems in lactococci, pp. 52-105 in Genetics and biotechnology of lactic acid bacteria. Gasson, M.J. and de Vos, W.M. (eds.) Chapmann and Hall, London.

2. de Ruyter, P.G.G.A., Kuipers, O.P., and de Vos, W.M. 1996. Controlled gene expression systems for Lactococcus lactis with the food-grade inducer nisin. Appl. Environ. Microbiol. 62:3662-3667.

3. Gasson, M.J. 1996. Lytic systems in lactic acid bacteria and their bacteriophages. Anton Leeuwenhoek Int. J. Gen. M. 70:147-159.

4. Buist, G., Kok, J., Leenhouts, K.J., Dabrowska, M., Venema, G., and Haandrikman, A.J. 1995. J. Bacteriol. 177:1554-1563.

5. Young, R. 1992. Bacteriophage fysis: mechanism and regulation. Microbiol. Rev. 56:430-481

6. Young, R. and Blasi, U. 1995. Holins: form and function in bacteriophage lysis. FEMS Microbiol. Rev. 17:191-205.

7. Sable, S. and Lortal, S. 1995. The lysins of bacteriophages infecting lactic acid bacteria. Apol. Microbiol. Biotechnol. 43:1-6.

8. Bläsi, U. and Young, R. 1996. Two beginnings for a single purpose: the dual-start holins in the regulation of phage lysis. Mol. Microbiol. 21:675-682.

9. O'Sullivan, D.J., Walker, S.A., West, S.G., and Klaenhammer, T.R. 1996. Development of an expression strategy using a lytic phage to trigger explosive plasmid amplification and gene expression. Bio/Technology 14:82-87.

10. Shearman, C.A., Jury, K, and Gasson, M.J. 1992. Autolytic Lactococcus lactis expressing a lactococcal lysin gene. Bio/Technology 10:196-199.

11. Shearman, C.A., Jury, K.L., and Gasson, M.J. 1994. Controlled expression and structural organization of a Lactococcus lactis bacteriophage lysin encoded by two overlapping genes. Appl. Environ. Microbiol, 60:3063-3073.

12. Kuipers, O.P., Beerthuyzen, M.M., de Ruyter, P.G.G.A., Luesink, E.J., and de Vos, W.M. 1995. Autoregulation of nisin biosynthesis in Lactococcus lactis by signal transduction. J. Biol. Chem. 270: 27299-27304.

13. de Ruyter, P.G.G.A., Kuipers, O.P., Beerthuyzen, M.M., van Alen-Boerrigter, I.J. and de Vos, W.M. 1996. Functional analysis of promoters in the nisin gene cluster of Lactococcus lactis. J. Bacteriol. 178:3434-3439.

14. Platteeuw, C. and de Vos, W.M. 1992. Location, characterization and expression of lytic enzyme-encoding gene, lytA, of Lactococcus lactis bacteriophage $\Phi$ US3. Gene 118:115-120.

15. Platteeuw, C., van Alen-Boerrigter, I., van Schalkwijk, S., and de Vos, W.M. 1994 Food-grade cloning and expression system for Lactococcus lactis. Appl. Environ. Microbiol, 62:1008-1013.

16. van Alen-Boerrigter, I.J., Baankreis, R., and de Vos, W.M. 1991. Characterization and overexpression of the Lactococcus lactis pepN gene and localization of its product, aminopeptidase N. Appl. Environ. Microbiol. 57:2555-2561.

17. Tan, P.S.T., Vankessel, T.A.J.M., Vandeveerdonk, F.L.M., Zuurendonk, P.F., Bruins, A.P., and Konings, W.N. 1993. Degradation and debittering of a tryptic digest from beta-casein by aminopeptidase-N from Lactococcus lactis subsp. cremoris WG2. Appl. Environ. Microbiol. 59:1430-1436.

18. Casadaban, M.J. and Cohen, S.N. 1980 . Analysis of gene control signals by DNA fusion and cloning in Escherichia coli. J. Mol. Biol. 138:179-207.

19. Sambrook, J., Fritsch, E.F., and Maniatis, T. 1989. Molecular cloning: a laboratory manual, 2nd ed. Cold Spring Harbor Laboratory, Cold Spring Harbor, NY.

20. Wells, J.M., Wilson, P.W., and Le Page, R.W.F. 1993. Improved cloning vectors and transformation procedure for Lactococcus lactis. J. Appl. Bacteriol. 74:629-636.

21. Vos, P., van Asseldonk, M., van Jeveren, F., Siezen, R.J., Simons, G., and de Vos, W.M. 1989. A maturation protein is essential for the production of active forms of Lactococcus lactis SK11 serine proteinase located in or secreted from the cell enveiope. J. Bacteriol. 171:2795-2802

22. Hiltier, A.J. and Jago, G.R. 1982. L-Lactate dehydrogenase, FDP-activated, from Streptococcus cremoris. Methods Enzymol 89:362-367. 